\title{
TIMELY RELAPAROTOMY AFTER CAESAREAN SECTION OF A MORIBUND PATIENT CAN SAVE THE LIFE
}

\author{
SAHA MR ${ }^{1}$, ARA I $^{2}$, ROY SC ${ }^{3}$, SAHA TK ${ }^{4}$, PAUL N ${ }^{5}$, SAHA TK ${ }^{6}$
}

\begin{abstract}
:
The aim of this study was to find out the outcome of cases requiring relaparotomy following caesarean delivery during the puerperium. This was a retrospective descriptive study set in a tertiary referral and teaching hospital i.e. Dhaka Medical College Hospital, Dhaka. Over a period of one year from January $1^{\text {st }}$ to $31^{\text {st }}$ December 2010, there were 5027 caesarean deliveries (53\%-94\%) out of a total of 9320 deliveries. Relaparotomy was done in 48 patients (0.95\%) of the caesarean sections. The indications of repeat laparotomy were secondary postpartum haemorrhage (PPH) in 28 cases (58.33\%), primary PPH due to uterine atony in 15 cases (31.3\%), uterine sepsis with haemorrhage in 2 cases (4.17\%), rectus sheath haemotoma in 2 cases (4.13\%), internal haemorrhage after caesarean section in 1 case (2.08\%). Of these 48 cases, in 14 cases, primary caesarean section was done in this institution while 34 had caesarean delivery at other hospitals and clinics at (13 cases) and outside Dhaka (21 cases). Main surgeries performed at relaparotomy were subtotal hysterectomy in 29 cases, total hysterectomy in 9 cases, drainage of haematoma and peritoneal toileting in 4 cases, resuturing of uterine incisions in 5 cases, internal iliac arteries in 1 case. More than one procedure was often performed in one case. There were 6 maternal deaths following relaparotomy caused by shock following PPH, septicaemia and internal haemorrhage. Repeat laparotomy within six weeks of caesarean delivery was required 1 in 200 cases in this institute. Case fatality rate was (12.5\%). Near miss fatalities were common. Majority on these were preventable. Identification of risk factors, adequate attention during primary surgery, expert decision, prompt intervention and proper case management during relaparotomy will improve the outcome. Centers carrying out caesarean section should have efficient blood transfusion service in the first place.
\end{abstract}

Keywords: Caesarean delivery, relaparotomy.

J Dhaka Med Coll. 2014; 23(1) : 41-47.

\section{Introduction:}

Cesarean section (CS) is the most common obstetric operation carried out in daily obstetric practice and the incidence has shown a dramatic increase over the last few decades globally ${ }^{1}$. With the improvement of operative technologies, anesthesia coverage and blood transfusion facilities, safety of cesarean section has increased considerably. Still it is a major operation and is associated with certain risk and complications. Complications rate associated with cesarean section is known to be several fold than that of vaginal deliveries ${ }^{2,3}$. This may be due to the under pathology of the primary indication for the operation or the quality of the surgery.

In some cases, the complications mandates a repeat laparotomy- (relaparotomy) requiring the patient to undergo surgery. Most of the time, relaparotomy is performed when the condition of the patient is too critical to withstand the risk of anesthesia and require the surgery. Often it is a very difficult decision and requires a good clinical judgment. On one hand it is the

1. Dr. Mukti Rani Saha, Junior Consultant, Department of Obstetrics \& Gynaecology, Tejgaon Health Complex, Dhaka.

2. Prof. Iffat Ara, Professor, Department of Obstetrics \& Gynaecology, Dhaka Medical College, Dhaka.

3. Lt. Col. (Dr.) Suvash Chandra Roy, CO, 15 field Ambulance, Ghatail, Tangail.

4. Dr. Tapan Kumer Saha, Associate Professor, Department of Surgery, Dhaka Medical College, Dhaka.

5. Dr. Nandita Paul, Junior Consultant, Cardiology, OSD, DGHS, Dhaka.

6. Dr. Tarun Kumar Saha, Medical Officer $(\mathrm{MCH})$, Vedarganj Upazila Health Complex, Shariatpur.

Correspondence: Dr. Mukti Rani Saha, Junior Consultant, Department of Obstetrics \& Gynaecology, Tejgaon Health Complex, Dhaka. Cell Phone: +8801715222508. 
last resort to save the mother's life, and on the other hand, the mother's reproductive capability is sacrificed in most of the cases ${ }^{4.5}$. Hence, relaparotomy may be considered as a near miss maternal mortality situtation ${ }^{6}$. Postpartum haemorrhage (PPH) following CS both primary and secondary, intraperitoneal haemorrhage, septicaemia, burst abdomen, rectus sheath haemotoma have been encountered as common indications of relaparotomy following cesarean delivery ${ }^{6,7}$. There are very few large scale studies on relapartomy following cesarean section and the maternal mortality and morbidities associated with relaparotomy has not been studied in detail. Dhaka Medical College Hospital is the most well known tertiary referral and teaching government hospital located in the centre of the capital dealing with all types of obstetric emergencies referred from urban, peri-urban and rural hospitals and clinics.

The objective of this study was to find out the incidence indications, risk factors and outcome of cases requiring relaparotomy following cesarean delivery done either in this institute or referred from outside hospitals. In this study we critically evaluated the cases of relaparotomy following cesarean delivery to identify the risk situations and the suggestions and precautions to be taken to improve the quality of care for preventing this dreadful complication of cesarean section.

\section{Methods:}

This was a retrospective descriptive study done in the Department of Obstetrics \& Gynaecology, Dhaka Medical College Hospital (DMCH), Dhaka, over a period of one year from $1^{\text {st }}$ of January to $31^{\text {st }}$ December, 2010. Over this period 5027 cesarean deliveries were performed in this hospital out of total of 9320 deliveries. Cesarean section rate was $53.94 \%$. Relaparotomy was done in 48 patients and the rate was $0.95 \%$ of the cesarean section. Dhaka Medical College Hospital has a wide catchment area and the referrals are received from other hospitals and clinics in the city and from nearby outside peri-urban and rural hospitals. Of these 48 cases, in 14 cases primary operations (cesarean section- which may be called primary
CS) was done in this institute while 34 had primary CS at other hospitals and clinics of Dhaka City. Fifteen cases were referred from hospitals and clinics outside the Dhaka City. Delivery under the direct assistance and guidance of the senior surgeons like residential surgeon and professors. All cases requiring repeat laparotomy within 6 weeks of primary CS were analyzed. The data of the patients were obtained from patients' medical history sheets, operation theater records, discharge certificates and referral notes of the primary CS. The following data were collectedage, parity, indications of primary CS, indications of relaparotomy, time interval from primary CS to reopening, procedure under taken on repeat operation, total units of blood transfused, duration of hospital stay and the outcome following relaparotomy. Data analysis was done by mean, median, percentage.

\section{Results:}

There were a total 5027 cesarean deliveries out of total of 9320 deliveries for the period under the study and the cesarean section rate was quite high (53.94\%). Fourty eight patients $(0.95 \%)$ required relaparotomy. The ages of the patients ranged from 15 to 35 with a mean of 27 years. The parity ranged form 1 to 5 with a median of 2. All the patients were house wife and none of them were working lady. Six patients were very poor and the rest 18 came from average socio economic condition. Only 8 patients had regular antenatal cheek up, 20 had irregular follow up and 20 patients did not have any checkup. Thirty four patients had C/ $\mathrm{S}$ at term, nine with gestational age less than 37 weeks and five patients were post dated. Six patients had one CS delivery before (post cesarean pregnancy) while 2 patients had 2 previous CS delivery (repeat cesarean pregnancy) in the past. None of the cases had primary elective cesarean section and all were done on emergency basis.

Table-I shows the commonest indication for repeat surgery was post partum haemorrage (PPH) in 38 cases $(79.17 \%)$ of which secondary $\mathrm{PPH}$ cases were $22(45.8 \%)$ and primary PPH due to uterine atony were in 16 cases (33\%). Rectus sheath haematoma occured in 4 cases 
$(8.3 \%)$ and was included in these series as peritoneal cavity was explored in both of these cases in addition to drainage of haematoma. Table-II describes the indications of primary CS and number of patients needed relaparotomy in the study population. Of these 48 relaparotomy cases all had undergone emergency CS and the commonest indication of primary CS was post CS and repeat CS Pregnancy $(12+4) 16$ cases. All the post CS and repeat CS cases came with prolonged labour. A more careful study of the primary indications and their relative risk for repeat laparotomy were analyzed. Table-III summarizes the procedures undertaken at relaparotomy. Main surgeries performed at relaparotomy were total hysterectomy in 25 cases and subtotal hysterectomy in 11 cases. Table-IV summarizes the time interval between primary CS and relaparotomy. Total 18 cases had relaparotomy within 24 hours. These were the cases of primary PPH (16 cases) and two with internal haemorrahage. Only one patient had relaparotomy within 6 hours of primary operation. In majority of the secondary $\mathrm{PPH}$ cases (18) relaparotomy was done after the first week of operation. Table-V describes the case fatality in details. A total of 6 patients died following resurgery with a case fatality rate about $12.5 \%$ (6 out of 48 ).

Table-I

Indications of relaparotomy

\begin{tabular}{lcc}
\hline Indications & Number of cases $(\mathrm{n}=48)$ & Percentage \\
\hline Postpartum Haemorrhage & 38 & 79.17 \\
a. Primary PPH & 16 & 33 \\
b. Secondary PPH & 22 & 45.8 \\
Rectus Sheath Haematoma & 4 & 8.3 \\
Uterine Sepsis with haemorrhage & 2 & 4.17 \\
with septicaemia & & \\
Internal haemorrhage from CS wound & 2 & 4.17 \\
Burst abdomen & 2 & 4.17 \\
\hline
\end{tabular}

Table-II

Indications of Caesarean delivery among the women who underwent laparotomy

\begin{tabular}{lcc}
\hline Indication for CS delivery & $\begin{array}{c}\text { Number of patients } \\
\text { delivered with this } \\
\text { indication in the } \\
\text { study period }\end{array}$ & $\begin{array}{c}\text { Number of patients } \\
\text { needed relaparotomy } \\
(\mathrm{n}=48)\end{array}$ \\
\hline Post Cesarean Pregnancy (1CS before) & 293 & 12 \\
Repeat CS ( ${ }^{3}$ 2CS before) & 63 & 4 \\
Obstructed Labour & 181 & 12 \\
Prolonged Labour & 134 & 3 \\
Foetal Distress & 177 & 5 \\
APH with Placenta Praevia & 74 & 2 \\
Heart disease & 56 & \\
Unknown & 7 & 3 \\
\hline
\end{tabular}


Table-III

Procedures undertaken during relaparotomy

\begin{tabular}{lcc}
\hline Procedure Undertaken & $\begin{array}{c}\text { Number of Cases } \\
(\mathrm{n}=48)\end{array}$ & Percentage \\
\hline Subtotal Hysterectomy & 12 & $25 \%$ \\
Total Hysterectomy & 25 & $52.1 \%$ \\
Bilateral Uterine Artery Ligation & 2 & $4.16 \%$ \\
Internal Iliac Artery Ligation & 1 & $2.1 \%$ \\
Resuturing of Uterine Incision & 1 & $2.1 \%$ \\
Repair of Bladder Injury & 2 & $4.16 \%$ \\
Drainage of Blood Clots from Undersurface of & 2 & $4.16 \%$ \\
Rectus Sheath and Peritoneal Cavity Toileting & & \\
Repair of Anterior Abdominal wall & 1 & $2.1 \%$ \\
Repair of Intestinal Injury & 1 & $2.1 \%$ \\
Splenic artery ligation and splenectomy & 1 & $2.1 \%$ \\
\hline
\end{tabular}

Table-IV

Time interval from CS to relaparotomy and their indications

\begin{tabular}{llc}
\hline Time interval from & Indications of Relaparotomy & Number of Cases $(\mathrm{n}=48)$ \\
\hline $\begin{array}{l}\text { Primary CS to Relaparotomy } \\
\text { Within 24 Hours }\end{array}$ & Primary PPH: 16 & 18 \\
& Internal Haemorrhage: 2 & \\
Within $7^{\text {th }}$ POD & Secondary PPH : 4 & 6 \\
& Rectus Sheath Haematoma : 2 & 16 \\
Within $8^{\text {th }}$ to $15^{\text {th }}$ POD & Secondary PPH: 10 & \\
& Rectus Sheath Haematoma : 2 & \\
& Burst Abdomen: 2 & \\
& Septicaemia : 2 & 8 \\
Within $16^{\text {th }}$ to $42^{\text {nd }}$ POD & Secondary PPH- 8 & \\
\hline
\end{tabular}

Table-V

Maternal mortality following relaparotomy

\begin{tabular}{|c|c|c|c|c|}
\hline $\begin{array}{l}\text { Causes of } \\
\text { Death }\end{array}$ & $\begin{array}{l}\text { o. deaths } \\
(n=6)\end{array}$ & $\begin{array}{l}\text { Indications of } \\
\text { relaparotomy }\end{array}$ & $\begin{array}{l}\text { Indication of } \\
\text { Caesarean delivery }\end{array}$ & $\begin{array}{l}\text { Time interval } \\
\text { from relaparotomy } \\
\text { to death. }\end{array}$ \\
\hline $\begin{array}{l}\text { Haemorrhagic } \\
\text { shock }\end{array}$ & 3 & $\begin{array}{l}\text { Broad ligament } \\
\text { haemotoma - (1) } \\
\text { PPH (2) }\end{array}$ & $\begin{array}{l}\text { Obstructed } \\
\text { labour (1) placenta } \\
\text { praevia (2) }\end{array}$ & $\begin{array}{l}\text { Within } 12 \mathrm{~h} \\
\text { within } 8 \mathrm{~h}\end{array}$ \\
\hline Coagulation failure & re 1 & $\begin{array}{l}\text { Abdominal } \\
\text { distension and shock (1) }\end{array}$ & $\begin{array}{l}\text { Previous C/S } \\
\text { with PIH with Jaundice (1) }\end{array}$ & Within $30 \mathrm{~h}$ \\
\hline Renal failure & 2 & PPH (atonic uterus) (1) & $\begin{array}{l}\text { Obstructed labour (1) } \\
\text { Fetal distress (1) }\end{array}$ & $\begin{array}{l}\text { Within } 3 \text { days } \\
\text { Within } 16 \mathrm{~h}\end{array}$ \\
\hline
\end{tabular}




\section{Discussion:}

In this descriptive study the incidence, indications, risk factors of cases requiring relaparotomy in the puerperium following cesarean deliveries and analysis of case fatalities associated with reopening of the abdomen were analyzed. There were very few published case series in the world literature regarding this repeat laparotomy. Along with the rising trends of cesarean deliveries, especially at tertiary level, obstetricians are now dealing with this complicated procedure associated with high risk of morbidities and mortalities. One study from a teaching hospital in Ghana with a CS rate of $17 \%$ showed a relaparotomy rate of $0.7 \%$ out of a total of 36012 deliveries. ${ }^{7}$ Another study from India showed a relaparotomy rate of $0.33 \%$ out of $12967 \mathrm{CS}$ deliveries (CS rate $34.8 \%$ ). ${ }^{6}$ In our hospital, CS rate was $58.94 \%$ during the study period and repeat laparotomy was noted in $0.95 \%$ of cesarean section. So the incidence was found more or less similar in these three studies although the CS rate was quite high in our hospital similar to the Indian study. ${ }^{6}$ In Ghana study, commonest indication of CS where relaparotomy needed was cephalo pelvic disproportion and obstructed labour and the commonest indication of relaparotomy was PPH due to uterine atony. ${ }^{7}$ The study in India also showed the same result, where the commonest indication of primary CS was prolonged and obstructed labour and the commonest reason for relaparotomy was PPH. ${ }^{6}$ Our study revealed that, the commonest indication of primary CS was post cesarean pregnancy followed by obstructed labour. PPH was the commonest reason for relaparotomy in our series similar to the findings of other studies. Although post caesarean pregnancy was the commonest indication, all the patients came with prolonged labour and home trial. One interesting findings was that among the PPH cases secondary PPH demanding relaparotomy was more $(45.8 \%)$ than the primary PPH cases due to uterine atony (33\%). The result is also consistent with the result of study in india where the secondary $\mathrm{PPH}$ accounts for $30.30 \%$ cases of relaparotomy. ${ }^{6}$ This findings demands special attention. Along with the rising trend of cesarean section rate the incidence of secondary PPH following CS is also increasing. In both of these cases we initially tried conservative management in the form of uterine massage, oxytocis such as injection oxytocic, ergometrine and misoprostol, fluid replacement and blood transfusion. In case of uterine atony we also explored the uterus for injuries and did intrauterine balloon catheter where needed. In case of secondary PPH, combination of injectable antibiotics covering Gram positive, Gram negative and anaerobic strains were also given. When the conservative management failled to stop the bleeding the surgical interventions were undertaken. Secondary PPH following CS was difficult to control. Exact causes of PPH could not be detected as exploration failed to detect any retained bits of placental tissues. On opening of the vesico-uterine pouch the wound found sloughed out in some cases with haemorrhage occurring from the sloughing margin. Uterus was found severely infected in other cases. All the secondary haemorrhage cases needed hysterectomy. Conservative surgery in the form of bilateral ligation of uterine vessels $(2$ cases) and of internal iliac artery (1case) were attempted and found successful in primary PPH cases. The management and findings were also similar with the Indian study where conservative surgery by vessel ligation were attempted but failed in 11 cases of secondary $\mathrm{PPH}$, who required a third laparotomy and eventually needed a hysterectomy. ${ }^{6}$ In an Australian study $\mathrm{PPH}$ too was found the commonest reason for relaparotomy. ${ }^{8}$ When conservative measures failed laparotomy followed by step wise ligation of vessele-B-Lynch sutures, bilateral uterine artery ligation, ligation of the utero ovarian anastomosis near the uterine cornue and internal iliac arteries ligation has been recommended but found effective only in $50 \%$ cases. ${ }^{9,10,11}$

Although the post CS pregnancy was found to be the commonest indication of the primary operation in this study, all these cases were referred cases. Detailed history revealed that all this cases were associated with prolonged labour. The second common reason for primary operation in this study was obstructed labour 
and the cesarean sections were done in second stage of labour. CS done in second stage with an impacted head could be technically difficult and is associated with increase trauma to the lower segment and lateral extension of tear to involve uterine vessels, cervix, vagina and bladder, increase haemorrhage and infection. ${ }^{12}$ In our study, repair of bladder injury was done in two cases along with total hysterectomy, one with the history of previous $2 \mathrm{CS}$ with prolonged labour and another with obstructed labour. Laceration in the lower segment of the uterus could be avoided during delivery of the impacted head by pushing the head up transvaginaly. ${ }^{12}$ All extension and laceration should be looked for in every difficult case for careful repairing to avoid subsequent traumatic PPH. ${ }^{13}$

Here, 38 cases relaparotomy was done for PPH. Out of 38 cases, conservative surgery in the form of bilateral ligation of uterine arteries (2 cases) and internal iliac artery ligation (1 case) were successful only in 3 cases. Rest of the 35 cases needed hysterectomy either total or subtotal. Total hysterectomy was also done in case where haemorrhage occurred from sloughing of uterine suture following sepsis. In case of internal haemorrhage from cesarean section wound resuturing of the uterine incision was done. Drainage of blood clots from undersurface of the rectus sheath and peritoneal cavity were done in 2 cases of rectus sheath haematoma. Peritoneal cavity was opened and inspected routinely in these cases. Cases of burst abdomen needed repair of anterior abdominal wall. Repair of bladder injury was done in two patients along with total abdominal hysterectomy one with 2 previous CS delivery and other with obstructed labour. Pregnancy with repeat cesarean setion also had repair of intestinal injury. More than one procedure was undertaken in one case.

Maternal mortality was quite high in patients who required relaparotomy following CS. In this study it was $12.5 \%$ ( 6 out of 48 ) where as mortality was $9.1 \%$ in African study and $12.1 \%$ in Indian study. ${ }^{6,7}$ Three patients died due to heamorrhagic shock with PPH within 8-12 hours of relaparotomy. One patient developed coagulation failure and died within 30 hours of relaparotomy. Indication of relaparotomy of that case was intraperitoneal haemorrhage and PPH with shock where the primary CS was done for revious CS pregnancy with PIH with jaundic. Another two patients died from renal failure within $16^{\text {th }}$ to 3 days of relaparotomy and indication of primary CS was obstructed labour and fetal distress. Among the maternal death all cases had emergency CS done outside the institute.

Those who survived six patients required admission to the intensive care unit and 12 patients required massive transfusion of more than 10 units of blood during and following surgery.

\section{Conclusion:}

The present study provides a profile of the patients who needed relaparotomy and their risk association in a tertiary teaching hospital. Although the cesarean delivery can be a life saving operation, serious complications could arise following the operation which mandates the patients to need another surgery. The maternal mortality and severe morbidity after relaparotomy are quite common. Obstetrics patients who need surgery all face near miss fatalities and potential risk of death. These cases demand judical decision and supervision by expert surgeons, good surgical technique to minimize haemorrhage and organ damage. In the post operative period these cases should be managed in the intensive care units.

Finally, it can be concluded that a lower CS rate will reduce the overall rate of complications including relaparotomy. At the time of decision making and counseling of risk patients possibility of these dangerous consequences must be remembered.

\section{References:}

1. Rouf S, Siddique SF, Mian AH, Begum A. The rising trend for Caesarean birth rate in a tertiary referral and teaching hospital. Bangladesh $\mathrm{J}$ Obstet Gynaecol 2000; 15: 15-23.

2. Depp R. Caesarean section and other surgical procedures. In Gabbe SG, Niebyl JR, Simposn JH, eds. Obstetrics: normal and problem pregnancies. $2^{\text {nd }}$ ed. New York: Churchill Livingstone; 1991: p.657-72. 
3. Rubin GL, Peterson HB, Robert RW, McCarthy BJ, Terry JS. Maternal death after Caesarean section in Georgia. Am J Obstet Gynaecol 1981; 139(6): 681-5.

4. Kant Anita, Wadhwani Kavita. Emergency Obstetric Hysterectomy. J Obstet Gynaecol India 2005; 55(2): 132-4.

5. Rouf S, Nasreen N, Begum J, Begum R, Begum A, Nahar S. Emergency peripaturm hysterectomy in a developing country. J Bangladesh Coll Phys Surg 2002; 20(2): 68-75.

6. Seal SI, Kamilya G, Bhattacharyya SK, Mukherji J, Bhattacharyya AR. Relaparotomy after Cesarean delivery: experience from an Indian teaching hospital. J Obstet Gynaecol Res 2007; 33(6): 804-9.

7. Seffah JD. Relaparotomy after Cesarean section. Int J Obstet Gynecol 2005; 88: 253-7.

8. Ashton P, Beischer N, Cullen J, Ratten G, Return to theatre - experience at the Mercy Maternity
Hospital, Melbourne 1971-82. Aust N Z J Obstet Gynaecol 1985; 25: 159-69.

9. Allahabadia G. Hypogastric artery ligation: a new perspective. J Gynaecol Surg 1993; 9: 35-42

10. Clark SL, Phalen JP, Yeh SY. Hypogastric artery ligation for obstetric haemorrhage. Obstet Gynaecol. 1985; 66: 353-63.

11. Cunningham FG, Leveno KJ, Bloom SL, Hauth JC, Gilstrap LC III, Wenstrom KD. eds. Williams' Obstetrics. $2^{\text {nd }}$ ed. New York: McGraw-Hill; 2005: p.828-54.

12. Fasubaa DB, Ezechi OC, Orji EO, et al. Delivery of the impacted head of the fetus at Caesarean section after prolonged obstructed labour: a randomized comparative study of two methods. Obstet Gynaecol 2002; 22: 375-8.

13. Ghosh TS, Kwawukume Ey. Delivery of the impacted fetal head at Caesarean section: surgical technique. Ghana Med J 1992; 28: 423-5. 